\title{
King's Termination Study II : Contraceptive Practice before and after Outpatient Termination of Pregnancy
}

\author{
R. W. BEARD, ELIZABETH M. BELSEY, SHIRLEY LAL, STELLA C. LEWIS, H. S. GREER
}

British Medical fournal, 1974, 1, 418-421

\section{Summary}

A selection of psychological and social factors present in 360 women who underwent legal termination of pregnancy are related to their contraceptive practice. One-third of the group were ignorant about contraceptive methods, ignorance being more common in women from social classes IV and $V$ and in those under the age of 19. Nearly half of those who had some knowledge of contraceptive practice became pregnant after knowingly taking a risk. A total of $41 \%$ had been using some form of contraception immediately before conception. The reliability of contraceptive methods used was found to be inversely related to neuroticism scores obtained from the Eysenck Personality Inventory, neuroticism being highest in women who had not used any form of contraception.

Of $91 \%$ of the group seen three months after their termination $86 \%$ were using reliable contraceptive methods. A follow-up study one or two years after termination has shown that $81 \%$ of the 215 women contacted so far are using a reliable method of contraception; two unwanted pregnancies have occurred but both were due to contraceptive failure. This satisfactory outcome has been ascribed to the system of counselling all women before and after termination.

\section{Introduction}

There is liotle doubt that the Abortion Act 1967 has improved the oppontunity for women in Britain who inadvertently become pregnant to decide whether they continue with the pregnancy. Yet most would agree that few women, given the choice, regard termination as a preferable alternative to avoidance of pregnancy. This being so, why is it, with contraception now readily available throughout the country, that so many unwanted pregnancies occur?

The experience reported in this paper is of a small group of women undergoing legal termination of pregnancy whose individual characteristics and behaviour were studied in depth. The study attempts to determine factors associated with unwanted pregnancies that may be of value for improving contraceptive use among women whom one can reasonably describe as being more "at risk" than the rest of the population. In addition the approaches adopted before and after termination to ensure avoidance of a further unwanted pregnancy, and their success, are reported.

King's College Hospital, London SE5

SHIRLEY LAL, B.A., Social Worker

STELLA C. LEWIS, M.B., M.R.c.o.G., Research Fellow

H. S. GREER, M.D., F.R.c.PSYCH., Consultant Psychiatrist

Department of Econometrics and Social Statistics, Southampton University, Southampton SO9 5NH

ELIZABETH, M. BELSEY B.sc., Teaching Fellow

Department of Obstetrics and Gynaecology, St. Mary's Hospital Medical School, London W2 1PG

R. W. BEARD, M.D., F.R.c.o.G., Professor

\section{Patients and Follow-up Procedures}

The study group consisted of a consecutive series of 360 women with first-trimester pregnancies referred by their general practitioners to the outpatient department at King's College Hospital. The management of patients, technique of abortion, and results have been described elsewhere. ${ }^{1}$

There were 144 married women and 179 single girls in the group. The remaining 37 were widowed, separated, or divorced. The social class of the married, widowed, separated, and divorced women was determined from the husband's occupation, and, for the single girls, from their father's occupation as classified by the Registrar General. The distribution of social class in the three London boroughs (Lambeth, Lewisham, and Southwark), from which many of the patients came was also considered (table I). Analysis of the results shows a significant difference $(P<0.0001)$ between the distribution of social classes in the study group, and in the general population of these boroughs. Social class distribution in the group was higher than expected for the area for the professional, semi-skilled, and unskilled classes (I, IV, and V) in that order; was the same for the intermediate class (II); and less for the skilled class (III). The ethnic origin of the patients was $67 \%$ Caucasian, $30 \%$ Negroid, and $3 \%$ Asian and other races.

TABLE I-Distribution of Social Class and Marital Status in the 326 Women

\begin{tabular}{|c|c|c|c|c|c|}
\hline \multirow{2}{*}{$\begin{array}{l}\text { Social } \\
\text { Class }\end{array}$} & \multicolumn{4}{|c|}{ Marital Status } & \multirow{2}{*}{$\underset{(\%)}{\text { G.L.C.C. }}$} \\
\hline & $\underset{(\%)}{\text { Married }}$ & $\underset{(\%)}{\text { Single }}$ & $\begin{array}{c}\text { Widowed/ } \\
\text { Separated// } \\
\text { Divorced (\%) }\end{array}$ & $\begin{array}{l}\text { Total } \\
(\%)\end{array}$ & \\
\hline $\begin{array}{l}\text { II } \\
\text { III } \\
\text { IV } \\
\text { V }\end{array}$ & $\begin{array}{r}9 \cdot 0 \\
5.6 \\
17 \cdot 4 \\
43.7 \\
24 \cdot 3\end{array}$ & $\begin{array}{c}10 \cdot 1 \\
20 \cdot 1 \\
21 \cdot 2 \\
27 \cdot 4 \\
21 \cdot 2\end{array}$ & $\begin{array}{r}5 \cdot 4 \\
8 \cdot 1 \\
27 \cdot 0 \\
46 \cdot 0 \\
13 \cdot 5\end{array}$ & $\begin{array}{r}9 \cdot 2 \\
13 \cdot 0 \\
20 \cdot 3 \\
35 \cdot 8 \\
21 \cdot 7\end{array}$ & \begin{tabular}{r|}
$3 \cdot 1$ \\
$12 \cdot 3$ \\
$55 \cdot 3$ \\
$16 \cdot 1$ \\
$13 \cdot 2$
\end{tabular} \\
\hline Total & 100 & 100 & 100 & 100 & 100 \\
\hline
\end{tabular}

*Data supplied by the Greater London Council. Source: 1966 Census.

All patients were asked to attend follow-up clinics 10 days, six weeks, and three months after the termination. A total of $88 \%$ of the women returned for the first of these and $87 \%$ for the second; $91 \%$ were seen at three months, the higher follow-up rate being achieved by visiting as many as possible of the nonattenders at home.

At the first attendance before termination the patient was interviewed by the social worker (S.L.) after seeing the doctor (S.C.L.). The interview with the counsellor had three aims: (1) to explain the procedure to the patient; (2) to review, with the patient, the reasons for the decision to have a termination; (3) to establish the sort of relationship with the patient that would enable the counsellor to assess her personality, attitudes, and possible response to the termination itself and to future contraception.

If an intrauterine device was to be inserted this was usually done 10 days after the termination, though in several women it was inserted immediately after evacuation of the uterus. Other forms of contraception were also usually prescribed at the 10-day clinic. At the three-month follow-up visit the reaction of the patient to the method of contraception agreed on was assessed. The need to continue using contraception was emphasized, even 
if regular intercourse was not taking place. Strong emphasis was placed on the creation of a personal relationship between the patient and the counsellor, and the success of such an approach can be judged from the high follow-up rate three months after the termination.

Some insight into the influence personality has on contraceptive use has been obtained by comparing the reliability of the method of contraception against neuroticism and extraversion scores obtained from the Eysenck Personality Inventory. ${ }^{2} \mathrm{~A}$ total of 308 women completed personality inventories at their first interview. Though it was recognized that most patients requesting termination would be in a state of emotional tension at this time it was felt that in-group comparison of scores relative to each other could be of some value.

The pill and intrauterine device are referred to as "reliable" methods because numerous studies ${ }^{3}$ have shown that they have the lowest failure rates. The sheath and cap are considered to be "less reliable," and vaginal foam and pessaries, coitus interruptus, and the safe period "unreliable" methods. A patient who knew of at least two reliable contraceptive methods is described as "informed." A woman who had regularly used any method of contraception for at least three months before the unwanted pregnancy is described as a "user."

\section{Results}

\section{KNOWLEDGE AND USE OF CONTRACEPTION BEFORE TERMINATION}

Marital Status.-The marital status of women in the group was related to their knowledge and use of contraception before termination (table II). As might be expected the married, single, widowed, separated, and divorced groups differed significantly in their use of contraception $(P<0 \cdot 0001)$. Over half of the married women were using contraception immediately before conception, compared with less than one-third of the single girls, and only just over one-third of the widowed, separated, and divorced group. Nevertheless, a very high proportion of the married women $(92 \%)$ and of the widowed, separated, and divorced women $(89 \%)$ had used contraception at some time compared with $65 \%$ of the single girls. Similarly the proportion of married women with knowledge of contraception tended to be higher than among the single girls.

TABLE II-Distribution by Marital Status of Contraceptive Knowledge and Use in the 308 Women

\begin{tabular}{|c|c|c|c|c|}
\hline $\begin{array}{l}\text { Marital } \\
\text { Status }\end{array}$ & $\begin{array}{c}\text { Informed } \\
(\%)\end{array}$ & $\underset{(\%)}{\text { Ignorant }}$ & $\begin{array}{l}\text { Users } \\
(\%)\end{array}$ & $\begin{array}{c}\text { Non-Users } \\
(\%)\end{array}$ \\
\hline $\begin{array}{l}\text { Married } \\
\text { Single } \\
\text { Widowed/ } \\
\text { Separated/ } \\
\text { Divorced . . }\end{array}$ & $\begin{array}{l}72 \cdot 2 \\
62 \cdot 0 \\
70 \cdot 3\end{array}$ & $\begin{array}{l}27 \cdot 8 \\
38 \cdot 0 \\
\\
29 \cdot 7\end{array}$ & $\begin{array}{l}56 \cdot 3 \\
30 \cdot 2\end{array}$ & $\begin{array}{l}43 \cdot 7 \\
69 \cdot 8 \\
\\
64 \cdot 9\end{array}$ \\
\hline Whole Group & $66 \cdot 9$ & 33.1 & $41 \cdot 1$ & 58.9 \\
\hline
\end{tabular}

TABLE III-Distribution of Contraceptive Knowledge and Use by Social Class in the 308 Women

\begin{tabular}{c|c|c|c|c}
\hline $\begin{array}{c}\text { Social } \\
\text { Class }\end{array}$ & $\begin{array}{c}\text { Informed } \\
(\%)\end{array}$ & $\begin{array}{c}\text { Ignorant } \\
(\%)\end{array}$ & $\begin{array}{c}\text { Users } \\
(\%)\end{array}$ & $\begin{array}{c}\text { Non-Users } \\
(\%)\end{array}$ \\
\hline II & 93.9 & 6.1 & 54.5 & 45.5 \\
III & 80.9 & 19.1 & 42.6 & 57.4 \\
IV & 80.8 & 19.2 & $45 \cdot 2$ & 54.8 \\
V & 60.5 & 39.5 & 40.3 & 59.7 \\
\hline Whole Group & 44.9 & $55 \cdot 1$ & 32.1 & 67.9 \\
\hline
\end{tabular}

Social Class. - Social class was related to knowledge and use of contraception before termination (table III). Knowledge was significantly higher $(P<0.0001)$ among women from social classes I and II (86\%) than in those from social classes IV and V $(55 \%)$, though the number of users was not significantly different.

Age.-As one might expect there was some relationship between age and knowledge and use of contraception. Of $\mathbf{4 2}$ single girls under 19 fewer were informed about contraception compared with the single women of 19 or over ( $40 \%$ compared with $69 \%, P<0.001)$, and fewer had been using it $(17 \%$ compared with $34 \%, \mathrm{P}<0.05$ ).

Eysenck Scores.-The neuroticism and extraversion scores of 308 patients as obtained from the Eysenck Personality Inventory were examined (table IV). The mean scores were compared with reported mean scores for a normal population ${ }^{2}$ and the scores obtained were also related to the methods of contraception used by our patients (table V). The neuroticism scores for the group were higher than those of the normal population, and were inversely related to the reliability of the contraceptive method used-that is, the highest mean score was found in the group of women who had used no contraception.

TABLE IV-Neuroticism $(N)$ and Extraversion $(E)$ Scores of 308 Women on the Eysenck Personality Inventory

\begin{tabular}{|c|c|c|c|c|}
\hline Group & & $\begin{array}{c}\text { Present } \\
\text { Sample } \\
(\mathrm{n}=308)\end{array}$ & $\begin{array}{c}\begin{array}{c}\text { Normal } \\
\text { Population }\end{array} \\
(\mathrm{n}=2,000)\end{array}$ & $\begin{array}{l}\text { Significance } \\
\text { of } \\
\text { Difference }\end{array}$ \\
\hline $\begin{array}{l}\text { Mean N score .. } \\
\text { Mean E score .. }\end{array}$ & $\begin{array}{l}\ldots \\
\ldots\end{array}$ & $\begin{array}{l}14 \cdot 57 \\
14 \cdot 07\end{array}$ & $\begin{array}{l}10 \cdot 52 \\
14 \cdot 15\end{array}$ & $\begin{array}{l}P=0.00005, \\
\text { Not significant }\end{array}$ \\
\hline
\end{tabular}

TABLE V-Neuroticism $(N)$ and Extraversion $(E)$ Scores Related to the Methods of Contraception used by the $308 \mathrm{Women}$

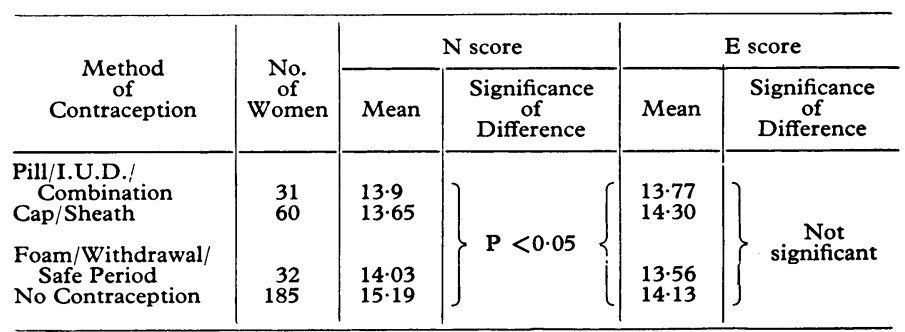

Reasons for Failure to Use Contraception.-All the women were asked about their contraceptive practice in the past as well as at the time the unwanted conception took place. A total of 212 $(59 \%)$ of the 360 patients admitted that they were not using a contraceptive at the time of conception; of these $37 \%$ had never used any form of contraceptive, while $63 \%$ had used some method in the past. A total of 138 women gave a single reason for having unprotected intercourse, while $\mathbf{7 4}$ gave two reasons (table VI).

Among the $148(41 \%)$ who were using some method of contraception at the time of conception, it is impossible to determine how many genuine method-failures there were, though of the $35(24 \%)$ patients who claimed to be using reliable methods 13 were on the pill and 17 were using intrauterine devices.

TABLE VI-Reasons Given by 212 Women (138 with one reason, 74 with two reasons) why Contraception was not Used at the Time of Conception. Results expressed as a percentage

Took a chance Unplanned intercourse Infrequent intercourse Ran out of supplies

Believed responsibility was husband's/boyfriend's Fear or antipathy to contraception. Offended morality (religion/standards) Pregnancy wanted to prove fertility Husband/boyfriend uncooperative Hospital/G.P./contraceptive clinic failure.
Others 


\section{CONTRACEPTIVE PRACTICE BEFORE AND AFTER TERMINATION}

Of the $\mathbf{3 2 6}$ women who returned to the final follow-up clinic only $43 \%$ were "users" before termination and only $25 \%$ of these were using a reliable method (table VII). Three months after termination, as a result of the advice given at the first follow-up clinic, some form of contraception was being used by $94 \%$ of women, of which $92 \%$ could be considered reliable (pill, intrauterine device, or sterilization).

TABLE vII-Contraceptive Use Among 326 Women who Attended Follow-up Clinic Three Months After Termination

\begin{tabular}{|c|c|c|c|c|c|c|}
\hline \multirow{2}{*}{$\begin{array}{c}\text { After Ter- } \\
\text { mination }\end{array}$} & \multicolumn{6}{|c|}{ Before Termination } \\
\hline & $\mathbf{A}$ & B & C & D & Total & Percentage \\
\hline $\begin{array}{l}\mathbf{A} \\
\mathbf{B} \\
\mathbf{C} \\
\mathbf{D}\end{array}$ & $\begin{array}{r}33 \\
0 \\
1 \\
1 \\
\end{array}$ & $\begin{array}{r}55 \\
5 \\
1 \\
3 \\
\end{array}$ & $\begin{array}{r}34 \\
1 \\
5 \\
1 \\
\end{array}$ & $\begin{array}{r}159 \\
10 \\
3 \\
14 \\
\end{array}$ & $\begin{array}{r}281 \\
16 \\
10 \\
19 \\
\end{array}$ & $\begin{array}{r}86.2 \\
4.9 \\
3.1 \\
5.8 \\
\end{array}$ \\
\hline Total & 35 & 64 & 41 & 186 & 326 & 100 \\
\hline Percentage & $10 \cdot 7$ & $19 \cdot 6$ & $12 \cdot 6$ & $57 \cdot 1$ & 100 & \\
\hline
\end{tabular}
Key to method of contraception: $A=$ pill, I.U.D., combination, or sterilized;
$\mathbf{B}=$ cap, sheath; $\mathrm{C}=$ foam, pessary, safe period, coitus interruptus; $\mathrm{D}=$ none.

There were 19 women who were using no form of contraception three months after their termination despite advice on the need to do so. Of these, 13 could see no purpose in taking contraceptive precautions because they had no partner. Two had a positive antipathy towards any form of contraception. Two, though having a partner, wished to abstain from intercourse until married, and two had regretted the termination and were attempting to become pregnant again.

A follow-up study in progress is examining the group one to two years after termination. So far the results have been obtained from 215 women. There have been two unwanted pregnancies (both contraceptive failures), seven have become pregnant from choice, and nine are trying to conceive. A total of 175 women $(81 \%)$ are using reliable methods of contraception, five are using unreliable methods, and three are having unprotected intercourse. The remaining 14 are not using contraception as they have no sexual partner.

\section{Discussion}

Legal termination of pregnancy may be viewed in isolation as a means of dealing with the problem of an unwanted pregnancy, or, as we have chosen to treat it, as an event that signals the need for help in a wider context. The justification for the latter approach is illustrated by the ignorance about and failure to use contraception by women in the study, and their tendency to neuroticism. The success of a sympathetic approach towards them and a liberal attitude to their request for termination of pregnancy is shown by the readiness with which they accepted advice on contraception and continued to use a reliable method for up to two years after termination. These observations apply to a group of women who are probably the least reliable users of contraception in the population.

Clearly the occurrence of an unwanted pregnancy is influenced by numerous factors. Many of them are difficult to determine, but several significant indicators have emerged in this study. Comparison of the social class distribution of women in the study with that in the area from which they were drawn shows that more women came from social classes I, IV, and V than expected. The higher representation of women from social classes IV and V is probably due to their relative ignorance of contraceptive practice ( $45 \%$ compared with $14 \%$ of women from social classes I and II), causing either ineffective use or total non-use of contraception. Certainly it seems reasonable to conclude that more effort should be devoted to educating women of low socioeconomic status in contraceptive practice. Neverthe- less, education in contraceptive practice does not appear to prevent unwanted pregnancies among women in social classes I and II who were poor users of contraception relative to their knowledge of it.

While there was no significant difference in knowledge of contraception between married and single women, its use was significantly lower among the latter. Knowledge of contraceptive practice is no guarantee that it will be used: motivation and the ease with which supplies can be obtained being equally important. ${ }^{4}$ Our finding that use was lowest among girls under 19 indicates that sex education in schools needs to be more positive about the consequences of unprotected intercourse.

The reasons given for failure to use contraception provide an interesting insight into the deficiencies of present contraceptive methods and how the vagaries of human nature are an important contributory cause of unwanted pregnancy (table VI). The fact that, despite knowing the risk, many of these women were prepared to take a chance that they would not become pregnant from unprotected intercourse suggests that there will always be some women who will be forced to seek legal termination of pregnancy. A total of one-third of the patients gave reasons for failing to use contraception such as offended morality, antipathy to contraception, and a desire to prove fertility-all of which have an emotional basis. These reasons show why, if another unwanted pregnancy is to be avoided, a full discussion between patient and counsellor about the underlying motivation is so important.

The problem of contraception is particularly difficult for the unmarried woman who has no regular partner. These women do not take the pill, because, though they accept that the need may arise, on balance they consider that the risks ascribed to the pill do not seem to justify prolonged use when intercourse is not taking place. Until recently nulliparous women were unable to use an intrauterine device, and even now, with smaller devices, the risks of infection do not encourage clinicians to prescribe them as the method of choice. A possible solution for them might be a contraceptive or early abortifacient that is effective at short notice.

Finally, some circumstances beyond the patient's control may result in an unwanted pregnancy. The comment by a doctor that the use of a particular contraceptive (usually the pill) carries some risk may be taken by the patient as an indication to stop contraception altogether. Such a warning should always be supported by advice from the doctor on a suitable alternative. Method failure is also a significant cause of unwanted pregnancies and, so far as we could determine, the incidence in this study was $20 \%$. A similar incidence of $18 \%$ was found among 922 women who requested termination at the Montreal General Hospital in 1972,5 and by Fraser and Watson ${ }^{6}$ studying women with unplanned full term pregnancies.

The reliability of contraceptive practices used by our patients was shown to be inversely related to neuroticism scores on the Eysenck Personality Inventory. Thus, women with the lowest neuroticism scores tended to use the most reliable methods of contraception whereas the patients scoring highest on neuroticism did not use any form of contraception. These results, which have not apparently been reported previously, require verification, but they suggest that neuroticism-which is akin to emotional instability ${ }^{2}$ - may be a significant contributory factor to unwanted pregnancy. We hope to explore the significance of the variables that make up the neuroticism score and other salient psychological and social variables which contribute to an unwanted pregnancy.

Hence we have shown that nearly all women can be persuaded to use some reliable method of contraception after termination, which subsequent experience shows is successful. A liberal and sympathetic approach to termination backed up by a fuli discussion of contraception will therefore usually ensure that a further unwanted pregnancy is avoided. Coincidentally it may have broader implications, providing many with a new start to a life that previously had many elements of unhappiness and frustration. 
We should like to thank Professor S. G. Clayton, Mr. J. M. Brudenell, and Mr. R. M. Feroze for providing us with all the facilities necessary to complete the study. We are particularly grateful to Sister Toon and her staff in the short-stay ward at Dulwich Hospital. Miss C. A. Knight provided invaluable help with the statistics. The study received generous support from the Simon Population Trust.

\section{References}

1 Lewis, C., Lal, S., Branch, F., and Beard, R. W., British Medical fournal, $1971,4,606$.

2 Eysenck, S. B., and Eysenck, H. J., Life Sciences, 1964, 3, 1103.

Bone, M., Family Planning Services in England and Wales, p. 18 . London, H.M.S.O., 1973.

4 Brennan, M. E., and Opit, L.J., British Medical fournal, 1973, 3, Suppl., 19

${ }^{5}$ Gillett, P., personal communication.

${ }^{6}$ Fraser, A. C., and Watson, P. S., Practitioner, 1968, 201, 351.

\title{
Instability of Polymeric Skin Collagen in Osteogenesis Imperfecta
}

\author{
M. J. O. FRANCIS, ROGER SMITH, ROBERT J. BAUZE
}

British Medical fournal, 1974, 1, 421-424

\begin{abstract}
Summary
The structural polymeric collagen of the skin of 19 patients with osteogenesis imperfecta has been examined. In those with severe bone disease, who often have white sclerae, this collagen fraction is less resistant to depolymerization than that of age-matched controls, though the total amount is normal. In patients with less severe bone disease, whose sclerae are usually blue, the polymeric collagen may have normal stability but the total amount is reduced. These results suggest defective cross-linking of collagen in severe osteogenesis imperfecta.
\end{abstract}

\section{Introduction}

Excessive fragility of the bones, which is the main feature of osteogenesis imperfecta (Seedorff, 1949; Albright and Grunt, 1971; King and Bobechko, 1971; McKusick, 1972), is probably due to a disorder of bone matrix (Follis, 1953; Falvo and Bullough, 1973). Its other features, such as blue sclerae, thin skin, and abnormal teeth, suggest that the defect is a generalized one involving those tissues which contain collagen. Since the overall metabolism of collagen is similar in all tissues (Grant and Prockop, 1972), and since the structural collagen of bone cannot be extracted unchanged for biochemical study (Steven, 1970) we have examined the physical and chemical features of the structural polymeric collagen of the skin (Francis and Macmillan, 1971; Francis et al., 1973).

In vivo structural polymeric collagen is present in fibres composed of extensively cross-linked networks of collagen molecules. The introduction of these cross-links is an important feature of collagen maturation during life (Bailey, 1968) and confers on connective tissue many of its physical and biochemical properties. Though some of these crosslinks have been charaoterized and methods are available for their estimation (Tanzer, 1973) the chemistry of most of them, especially those present in the collagen fibres of adult tissues, is unknown. We have therefore had to adopt an indirect method for studying these cross-links (Steven, 1966; Francis and Macmillan, 1971). This consists in preparing a

Nuffield Department of Orthopaedic Surgery, Nuffield Orthopaedic Centre, Headington, Oxford OX3 7LD

M. J. O. FRANCIS, D.PHIL., Lecturer in Biochemistry

ROGER SMITH, M.D., M.R.C.P., First Assistant

ROBERT J. BAUZE, M.B., F.R.A.C.S., Girdlestone Scholar polymeric fraction which contains collagen fibres having both the amino-acid composition and the typical electron-microscopical appearance of purified collagen. This fraction constitutes the major proportion (over $60 \%$ ) of total skin collagen and remains extensively cross-linked. Its stability to depolymerization is easily measured and provides, in these purified samples, an indirect estimate of cross-links present between the collagen molecules.

Our results, which show in particular that this form of collagen is unstable in severe osteogenesis imperfecta, are briefly discussed in terms of modern knowledge of collagen structure.

\section{Subjects and Methods}

Nineteen patients with osteogenesis imperfecta (table I) and 54 normal controls were studied. (The data on 49 controls have been discussed elsewhere (Francis et al., 1973).) The patients are listed in order of increasing age and divided into groups according to the colour of the sclerae. This was estimated clinically and by photography against a standard colour chart as either blue or intermediate or white (normal). The severity of the bone disease was assessed by the age at onset and the approximate total number of fractures. In a larger clinical series it was clear that those with severe bone disease have a high incidence of severe scoliosis and are often unable to walk and that such patients tend to have sclerae of normal colour. Those with blue sclerae tend to have less severe bone disease. The division according to scleral colour was used here because of its simplicity and may need future modification.

The biopsy specimens were usually of a diamond or an elliptical shape. In 10 patients (cases $2,3,5,6,9,10,13$, 15-17) they were of constant area $\left(85 \mathrm{~mm}^{2}\right)$ and in the remaining nine they were not measured. Skin biopsy specimens were taken from behind the greater trochanter in all patients except cases $2,11,14$, and 19 . In cases 2,11 , and 14 skin was obtained from an operative site. In all elective biopsies performed during life the procedure was explained to the patients and their consent was obtained. Skin from one patient (case 1) was obtained after death. All specimens were analysed immediately or kept deep frozen at $-20^{\circ} \mathrm{C}$.

The procedure for analysis has been described previously (Francis and Macmillan, 1971; Francis et al., 1973). We measured the following collagen fractions: the total skin collagen (related to area and to fat-free dry weight), the proportion of collagen soluble in $5 \%(\mathrm{w} / \mathrm{v}) \mathrm{NaCl}$, and the polymeric or structural collagen. Two polymeric collagen fractions were obtained. The major fraction, which comprises 65 to $85 \%$ of total skin collagen in normal adults, contains collagen fibres that are larger and more stable than the minor 